\title{
ROCK CORE ORIENTATION FOR MAPPING DISCONTINUITIES AND SLOPE STABILITY ANALYSIS
}

\author{
S. Ureel ${ }^{1}$, M. Momayez ${ }^{2}$, Z. Oberling ${ }^{3}$ \\ ${ }^{1}$ Dept. of Mining \& Geological Engineering, University of Arizona, Tucson, AZ USA, scott.ureel@gmail.com \\ ${ }^{2}$ Dept. of Mining \& Geological Engineering, University of Arizona, Tucson, AZ USA, mmomayez@email.arizona.edu \\ ${ }^{3}$ Call \& Nicholas, Inc., Tucson, AZ USA, zoberling@cnitucson.com
}

\begin{abstract}
Rock fabric data collected from oriented core provides supplemental information for slope stability analyses. Orientation of rock core during drilling programs has become extremely pertinent and important for slope stability and underground mining operations. Orientation is needed to provide essential data to describe the structure and properties of discontinuities encountered during the design process to understand favorable and unfavorable conditions within a rock slope and underground openings. This paper examines and discusses the limitations and benefits of four methods of obtaining borehole discontinuity orientations from drilling programs including clay-imprint, ACT I,II,III Reflex, EZY-MARK, and OBI/ABI Televiewer systems. Results, recommendations and conclusions are provided in this paper.
\end{abstract}

Index Terms: Orienting Core, Rock Drilling, Televiewer, Rock Orientation

\section{INTRODUCTION}

In the mining and civil engineering industries, slope stability is an important consideration for site safety, maximum ore removal and limited interruptions in production. Many aspects of rock slopes need to be investigated such as rock and hydraulic geometry, geological structures, laboratory properties and stress conditions to provide the highest safety potential. The most important properties of rock slopes that dictate optimal slope angles and rock control are the orientation of rock discontinuities or joints. Numerous methods have been introduced to obtain the orientation of rock discontinuities through drilling; however, only three methods are currently widely used in practice and during drilling programs at mine sites throughout the world.

Many times in the mining industry, engineers perform rock slope design using different types of analyses; however, it is essential to utilize oriented core logging to establish baseline geotechnical data to determine planes of weakness within the rock mass at depth. Once core orientation has been achieved, the data can be plotted on stereonets to determine where adversely oriented joint sets may occur. The following will examine rock core orienting techniques and discuss associated benefits and limitations for applying these methods in the field for rock core orientation.

\section{ROCK CORE ORIENTING}

Core orientation entails recording the orientation of geologic structures in core samples to obtain the in-situ position of discontinuities to determine favorable and unfavorable conditions of rock masses when analyzing the stability of rock slopes. During the orientation process, the in-situ locations of discontinuities are marked on the top or bottom of the core given by the chosen core orientation method (except televiewer imaging). The rock core is assembled together along a leveled edge such as a driller's split Shelby tube so the reference line can be drawn. Once the reference angle is measured in a goniometer (Figure 1), orientation of structures along the core run can be measured using a goniometer (Figure 2). The following parameters are important when recording data for each core run:

- Reference Angle

- Dip Angle (Alpha)

- Dip Direction Angle (Beta)

- Rock Type

- Depth

- Alteration

- $\quad$ Type of Structure

These parameters are extremely important for characterizing joint conditions and expressions as discontinuities generally dictate the mechanical behavior of bench-scale rock masses. The data provide essential information for designing and analyzing critical slip surface paths, slope angles and bench heights. It should be noted, traditional core orienting methods are most beneficial when used on angled drill holes to intercept as many geological structures and rock types as possible that are of geotechnical interest. 


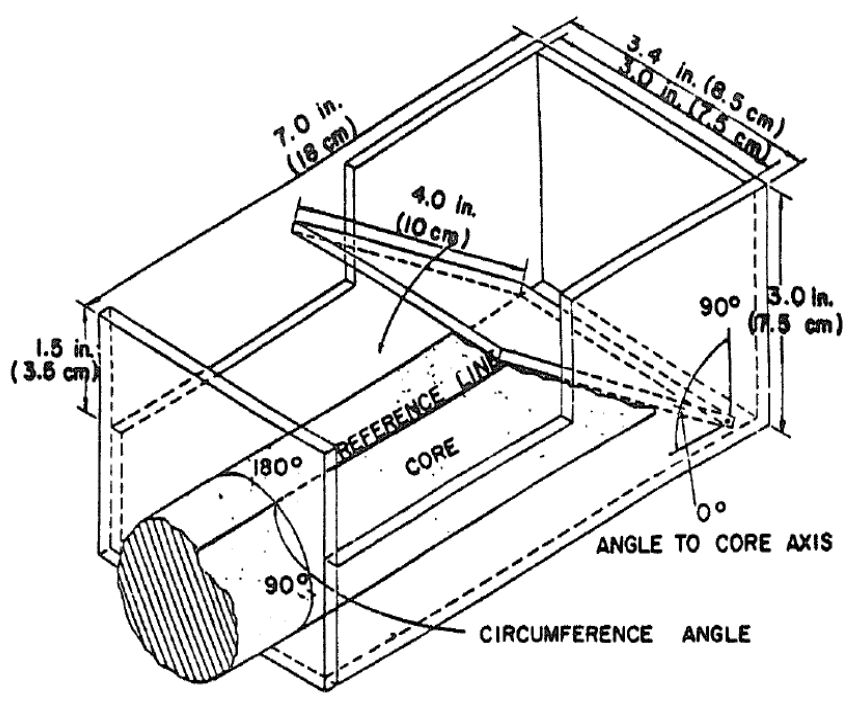

Figure 1: Goniometer used for core orientation

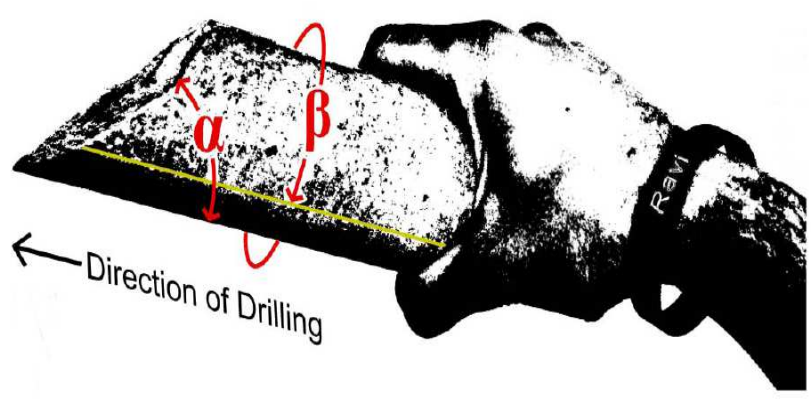

Figure 2: Basic visual of reference line, alpha and beta angles (Cylwik et. al 2011)

\section{FIELD METHODS FOR ORIENTATION}

When choosing the correct field method for rock orientation, the engineer or geologist needs to be aware of which method is the appropriate choice for varying engineering conditions. Several methods are available and all have inherent limitations and benefits; however, all methods have provided priceless information for mine design. Key considerations when choosing a field orientation method are:

- Accuracy and reliability of in-situ rock orientation data

- Cost

- Interruptions in drilling

- High performance rating (production rate)

- Difficulty in use

- Condition of rock mass

The following section will explain the concept of four popular orientation field methods and how each has made its contribution to rock orientation.

\subsection{Clay Imprint Apparatus}

The clay-impression method, originally developed by Call \& Nicholas, Inc. (CNI), was used to determine the true orientations of fractures from core drilling (Call, 1982). With the use of a inclined holes 40 to 70 degrees from a horizontal reference, the clay-impression method of orienting core allows for the determination of the true orientation of fractures by using an eccentrically weighted orientor (a core barrel halffilled with lead) to take a clay impression of the bottom of the hole. Based on a top-of-the-hole reading obtained from the clay impression, the logged orientation is transferred to the rock core to determine the alpha and beta angles based off a reference line. The apparent orientations can then be converted to true orientations. Modelling clay used for impression needs to be packed tightly within the apparatus and needs to extend far enough past the drill bit to make an accurate impression and also unsaturated if possible. If the rock core contains a smooth break at the end of the drill, orientation may not be possible.

The clay imprint method is not difficult to use relative to other methods and is based on simple concepts of core orientation. The cost is almost negligible and is the only method available that makes an actual imprint of the core condition. This method is not suitable for very discontinuous rock as putting the core together can be very difficult and the clay impression can be filled with fines and gravels. Furthermore, extensive drilling programs will result in higher costs as personnel are required on-site during drilling.

A basic concept of the clay imprint is shown in Figure 3. Figure 4 shows the engineer "matching" clay impression with bottom of the hole.

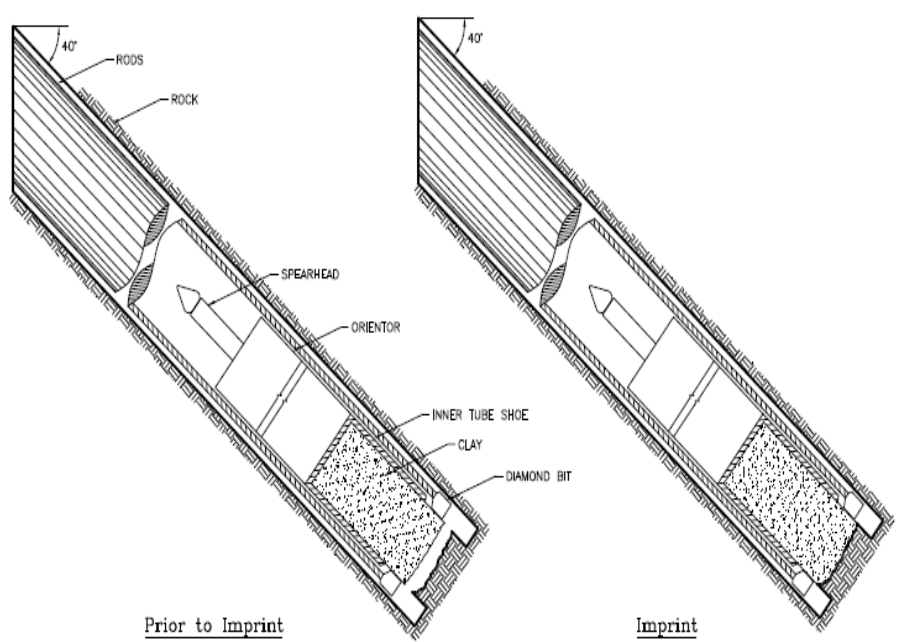

Figure 3: Clay orientor concept prior and during imprint (Call \& Nicholas, Inc. 2008) 


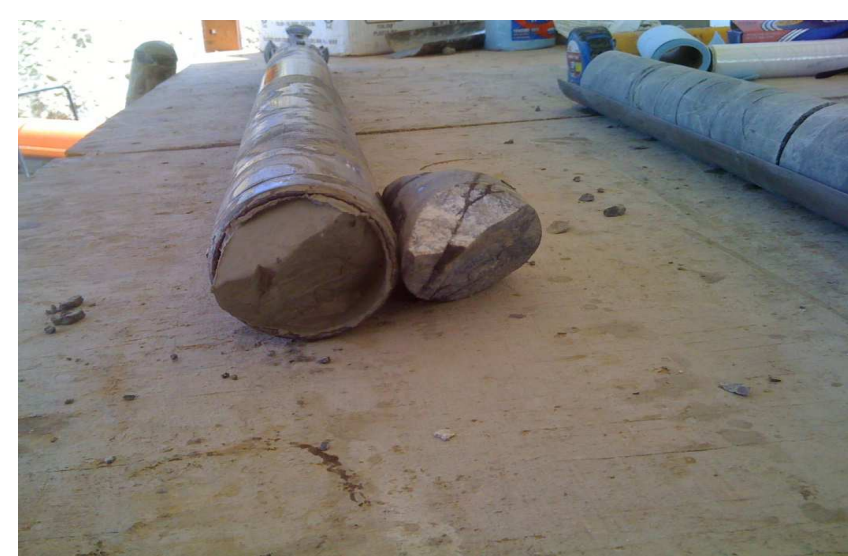

Figure 4: Determining top of hole marking by matching true orientation

\subsection{EZY-Mark Orientation}

The Ezy-Mark is a mechanical orientation tool located at the front of the inner tube that provides an auditable impression of the bottom of the hole before drilling commences and is manufactured by 2iC Australia Pty., Western Australia. The Ezy-Mark core orientation device is inserted into the drill inner tube and then sent down the drill hole. The inner tube is located behind the drill bit and dropped to the core break from the previous run and the instrument is activated making an impression of the core. During this time orientation balls are then locked into place to save the orientation. The drill operator then needs to pull back the instrument and touch the bottom of hole again. The instrument retracts and drilling can continue. Both the orientation tool and core are then brought to the surface to begin core orientation. The core is then matched with the impression made with the orientation screws locked by the orientation balls in the mechanism and an orientation line can be drawn. Figure 5 shows the Ezy Mark orientation tools and Figure 6 displays the engineer transferring the orientation from the orientation tool to the core.

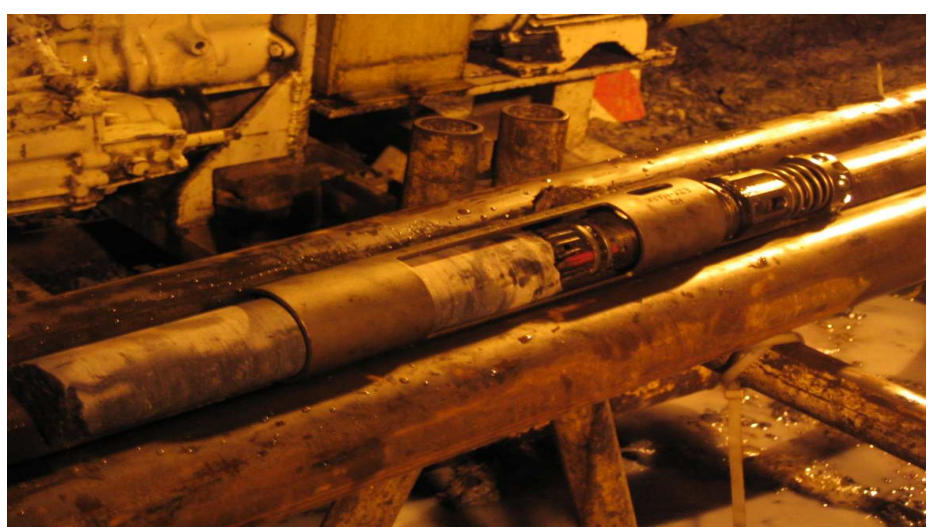

Figure 5: Ezy-Mark system

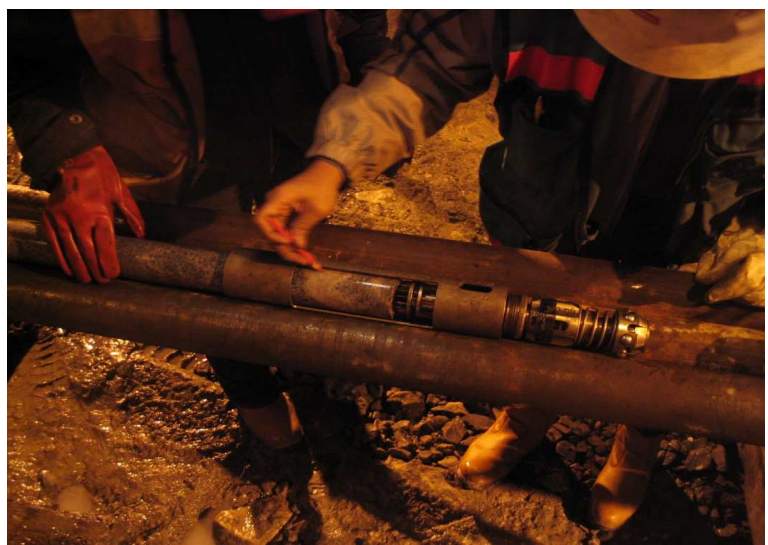

Figure 6: Transferring orientation to rock core using EzyMark system

\subsection{ACT Reflex (I, II, III) Orientation}

The Reflex ACT I, II, and III are core orientation devices developed by Reflex Instruments, a division of Imdex Limited, with the main office in Perth, Western Australia. Reflex instruments are becoming increasingly popular and are now being applied worldwide. The Reflex core orientation system is based on recovering the core barrel orientation at the conclusion of a given run. The Reflex orientation tool (Figure) begins the orientation process by inserting the tool in the core barrel using a specially made shoe. The tool records core barrel orientation each minute during a core run. The Reflex sleeve that attaches to the upper drill rod measures the orientation of the top-of-hole using built in accelerometers. Upon completion of a run, the drill string is left undisturbed while the communication tool, which is on the surface, counts down the time to the next reading; after this, the barrel can be withdrawn. On the surface, the tool is inserted into the end of the barrel and the barrel is rotated until the tool indicates that the barrel is in the same up-down position as it was in the hole. The core, barrel, and shoe are then marked using a spirit level to confirm verticality upward. After the liner is split, the top of core marks are transferred along the length of the recovered core. Figure displays the orientation tools and Figure exhibits the ACT II being used in an orienting core program.

The Reflex ACT II is a relatively easy instrument to use once the operator understands how orientation is achieved from the ACT instrument and how the instrument options operate. The ACT I the user needed to utilize a stopwatch instead of the ACT tool recording orientation every minute where ACT II \& III the timer is built into the Reflex instrument. Reflex instruments have now introduced the ACT III which contains more capabilities than both the ACT I \& II. Figure 7 exhibits the Reflex ACT II orientation tool and Figure 8 shows driller with the inserted instrument in the core barrel to either match the orientation mark or reset timer for next drill run. 


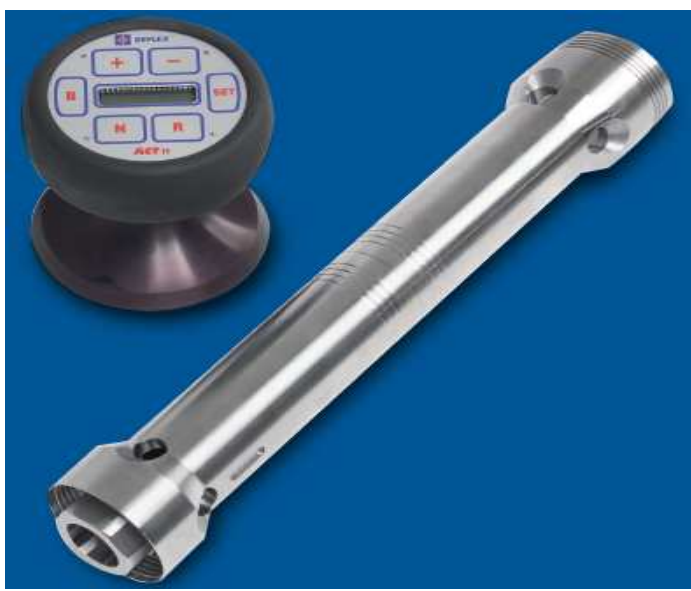

Figure 7: Reflex ACT II orientation tools (Reflex Instruments, 2013).

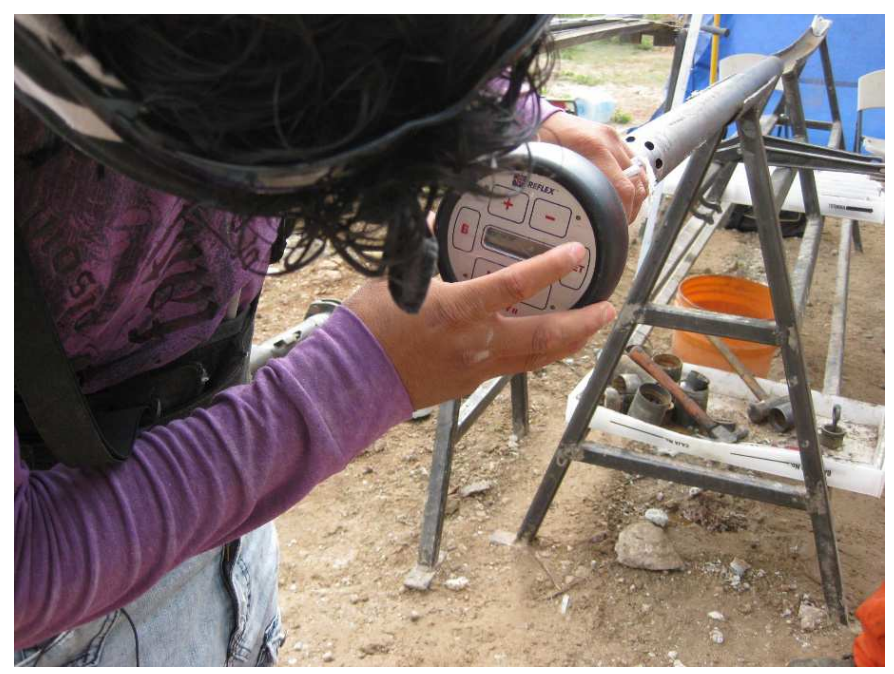

Figure 8: Using the Reflex ACT II tool to find orientation and reset timer

\subsection{Televiewer Orientation}

Televiewer imaging utilizes optical and acoustic waveforms emitted from a fixed source housed within a probe to map the borehole wall producing a near-continuous down-hole, photographic-like image of the borehole. The orientation of geologic features including fractures, faults, shear zones, bedding planes, sedimentary features, and veins can be obtained by both optical and acoustic borehole imaging methods (OBI and ABI, respectively).

The OBI probe incorporates a high resolution, high sensitivity CCD digital camera with matching Pentax optics and is used in clear fluid-filled or dry portions of the borehole. Optical imaging devices record contrasting colors of the rock and discontinuities to create a true color photograph of the borehole wall. Mud-filled holes are imaged by a probe outfitted with a sonar transducer that emits ultrasonic pulses at a range of specified intervals that are reflected off a rotating acoustic mirror. The amplitude and travel-time of reflected acoustic signals are measured and recorded simultaneously. Three-armed calipers are not required by ABI tools as the twoway travel-time log effectively represents the borehole diameter while recording any borehole irregularities or breakouts.

Processing and optimization of raw televiewer data into image logs allows the identification and documentation of discontinuities in the surveyed rock mass. Geologic features appear in image logs as fixed-period sinusoidal waveforms displayed from $0^{\circ}$ to $360^{\circ}$ (Figure 9). Note the point tangential to the sinusoids minimum equals the dip direction and dip degree $=\arctan (\mathrm{h} / \mathrm{d})$ with $\mathrm{h}=$ height of the waveform and $\mathrm{d}=$ diameter of the cylinder (borehole) in Figure 9. Orientation of the image log to geographic north allows calculation of discontinuity orientations with the amplitude and trough of the sinusoids corresponding to the dip degree and dip direction, respectively.

Acoustic borehole imaging is governed by differences in acoustic impedance between the drilling fluid and adjacent rock formation. Acoustic impedance $(\mathrm{Z})$ is defined by the following equation:

$$
Z=\rho \leqslant V
$$

where $\rho=$ density, and $\mathrm{V}=$ acoustic velocity. Acoustic signals are separated into transmitted and reflected waveforms at the rock/fluid interface (e.g. borehole wall) and the degree of waveform partitioning is directly dependent on the density and acoustic velocity contrast at the interface. The degree of energy partitioning for a wave that hits an interface at normal incidence is defined as the reflection coefficient or impedance mismatch. This is defined by the following equation:

$$
R=\frac{Z_{1}-Z_{0}}{Z_{1}+Z_{0}}
$$

where $\mathrm{R}=$ reflection coefficient and $\mathrm{ZO}$ and $\mathrm{Z1}$ equal the acoustic impedances of the first and second medium (e.g. drilling fluid and borehole wall), respectively. High impedance mismatches at the fluid/rock interface results in more acoustic energy being partitioned into reflected waveforms; therefore, the transducer receives higher amplitude signatures. Lower impedance mismatches result in more transmitted and less reflected energy at the interface effectively reducing the amount of energy received by the transducer. Amplitudes of reflected waveforms are illustrated on a false-gradational color scheme image log with low and high amplitude signals depicted as cold and hot colors, respectively. 


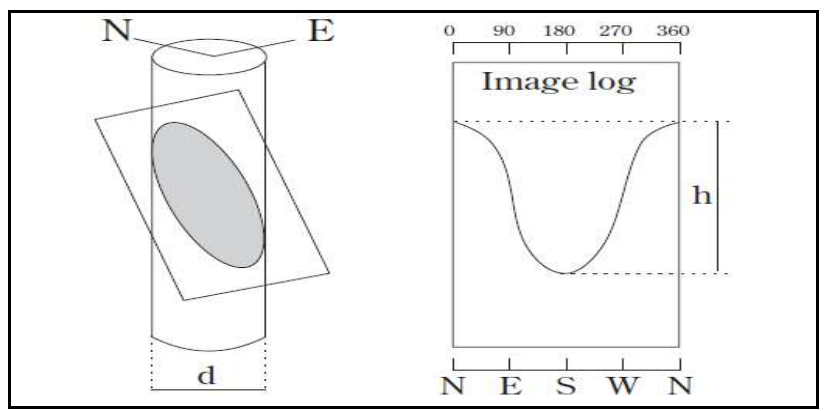

Figure 9: Projection of an inclined planar feature intersecting a cylinder and "unfolding" of the ellipse to $2 \mathrm{D}$ results in a fixed-period sinusoid. (Gaillot et al., 2007)

Interpretation of rock fabric orientation data from image logs can be highly subjective and the accuracy and reliability of $\mathrm{ABI}$ and OBI rock fabric orientation data are heavily dependent on the quality of the image log, ground/borehole conditions, and experience of the core logger. The quality of image logs may be reduced by numerous factors including improper surveying and data optimization and by rock mass/borehole conditions. Rock mass and borehole conditions that influence image log quality include:

- Style and pervasiveness of alteration.

- Rock and fracture-fill/discontinuity color (OBI only).

- Rock and fracture-fill/discontinuity density contrasts (ABI only).

- Geometry, frequency, filling thickness, spatial relation, and mineralogy of discontinuities.

- Borehole shape, rugosity, and diameter.

- Suspended dust content, fluid turbidity, and wall coatings (OBI only).

Optical and acoustic borehole imaging methods also require multiple steps to create the associated image log prior to discontinuity orientation data interpretation. Therefore, many instances exist in which errors can be introduced into the data. These errors may be introduced during surveying and data processing and optimization.

As optical borehole image logs represent true color contrasts, differing color combinations of rock and fracture-fill are primary controls in image log quality provided there are good borehole conditions (no coatings, dust, etc). In Figure 10A, The two vertical to sub-vertical bands with increased distortion (black arrows) indicate the probe was decentered during surveying. The vertical banding overprints geologic features reducing the quality of the image log introducing difficulties in confidently identifying and tracing sinusoids; partial sinusoids are observed (red arrows) but they cannot be confidently traced. This issue can be resolved by logging with the core present and validating dip degrees with a goniometer. Similarly colored rocks and discontinuities are generally not well represented and difficult to distinguish in image logs.
With all other factors equal, color contrast and sinusoid prominence are directly proportional; an increase in contrast generally corresponds to an increase in sinusoid prominence in the image log (Figure 10B). The image log contains highly distorted and low-resolution horizontal bands (black arrows) that indicate either a dirty optical lens or improper surveying techniques resulting in lost or poorly recovered data traces. The red arrows indicate potentially open fractures; however, without the core present, it can be extremely difficult to distinguish between open fractures, healed fractures, and veins. Note how darker colored sinusoids are readily apparent in the lighter colored host rock.

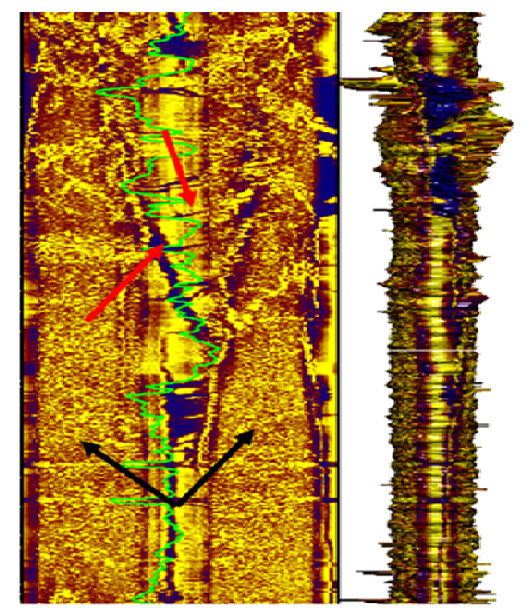

Figure 10(A). Acoustic borehole image of Fe-oxidized granite

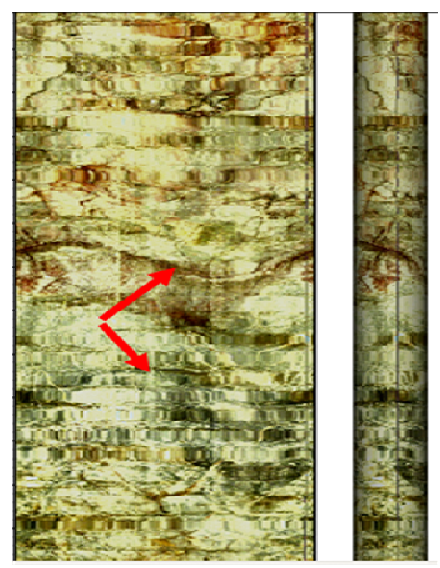

Figure 10(B). Optical borehole image of Fe-oxidized granite

For ABI, discontinuities typically appear as dark sinusoidal traces on the image $\log$ as they have lower impedance mismatches relative to the surrounding rock mass. (Figure 11A). However, if the fracture and/or fracture-fill lacks significant impedance mismatches relative to the surrounding rock mass (i.e. clay-filled fractures in a heavily sercitized 
granite), the fracture and surrounding rock will be illustrated as cold colors on the image log diminishing the core logger's ability to confidently identify and trace the sinusoid (Figure 11B). Even high quality image logs can result in the introduction of erroneous data if logged by unskilled personnel or without the rock core present. As illustrated by Figure 11A, numerous sinusoids are readily apparent but confidently differentiating between measurable open joints, healed fractures, and veins is problematic unless sinusoids in the image $\log$ can be successfully correlated to the same feature in the core. Optical and acoustic borehole imaging can be a reliable alternative to other core orienting methods if it is suitable for the project's needs, is properly managed at each level and is logged with the core present.

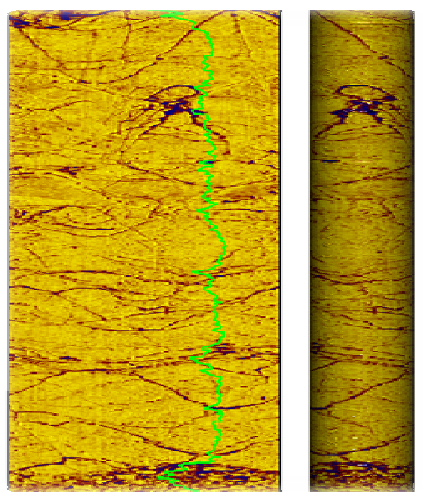

Figure 11A: Acoustic borehole image of relatively fresh monzonite) with quartz-sericite-pyrite (black arrows) veins and potentially open sericite/Fe-oxide-filled discontinuities

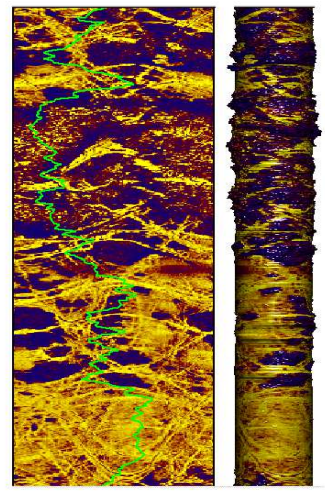

Figure 11B: Acoustic borehole image of heavily sercitized/argillized monzonite

\section{DISCUSSION}

The following section provides a discussion summary describing the benefits and limitations for the four methods presented in this paper. All methods are of great use; however, one may be better suited for weather, cost, workability, rock and drill-hole conditions. Table 1 illustrates a summary of the limitation and benefits for each method. Sections 4.1 to 4.4 will explain each method individually.

TABLE 1: Benefits and Limitation for Rock Orientation

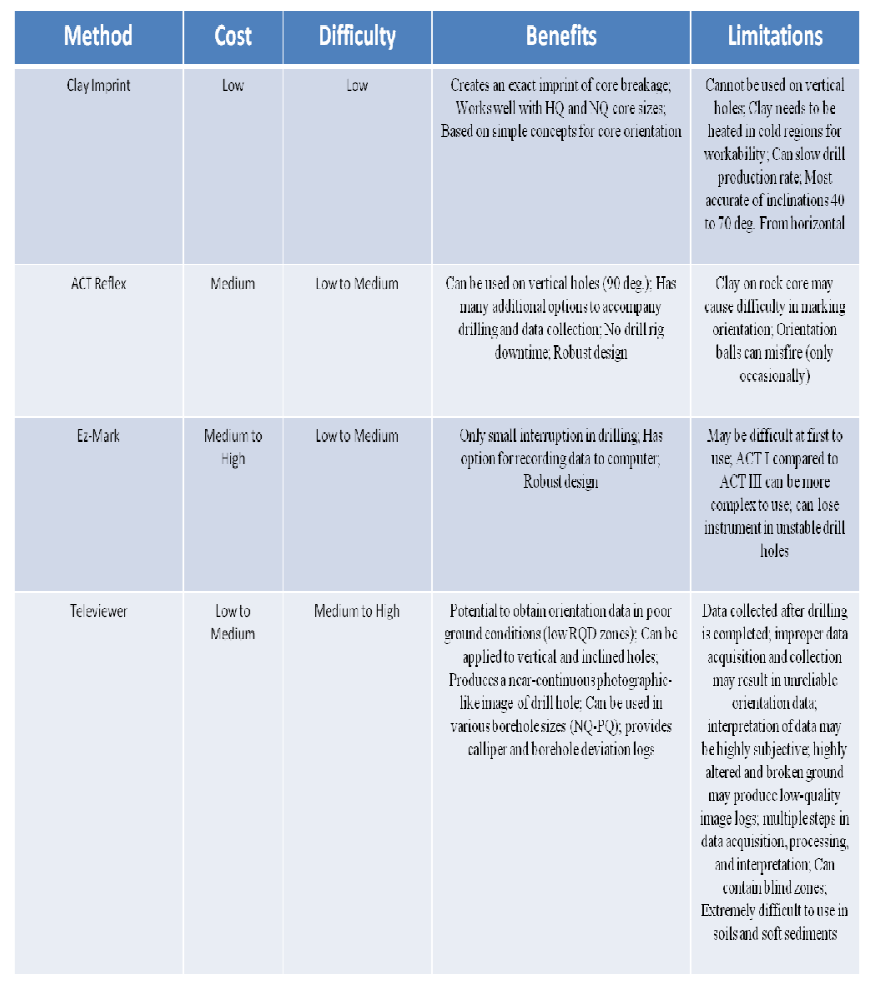

\subsection{Clay Imprint}

The clay imprint has proven very useful since its conception in the early 1970s. It has been used in numerous projects such as the Tazadit Pit in Mauritania, Africa (Call et al, 1982). The clay imprint is the simplest method to use; however, the clay apparatus needs to be specially made and the instrument can only be used on drill holes 40 to 70 degrees from the horizontal. The most unique concept of this method is the impression made of the bottom-of-hole giving the user an actual clay image.

\subsection{EZY-Mark Orientation}

The Ezy-Mark Orientation method provides the most versatile of the four methods. It continuously allows more and more options available for more accurate orientation such as the Verti-Ori and Ori-Block. This method was used on several projects including Freeport MacMoran Grasberg Project in Indonesia. Ezy Mark is retrieve real time data and allow no down drill time. Ezy Mark may not be appropriate for extremely discontinuous rock or rock with a large amount of clay layering. 


\subsection{Reflex ACT I, II, III}

The Reflex ACT orientation tools are very robust and made to handle bad weather conditions. The tools are rated to $6,000 \mathrm{psi}$ water resistance and resilience up to $50,000 \mathrm{G}$ 's of force (Reflex Instruments, 2013). The tool was used in extreme conditions at a high altitude mining project in the Peruvian Andes and showed no sign of damage. The Reflex tools become easy to use once the engineer has learned how the Reflex timer/computer works and provides real time data. The instrument can be lost in an unstable drill hole.

\subsection{Televiewer Orientation}

Many of the issues concerned with accurately interpreting discontinuity orientation data in OBI and ABI image logs associated with $\mathrm{OBI}$ and $\mathrm{ABI}$ can be resolved by logging with the rock core present. Benefits of logging with the core present include:

- Calculation of core/image log offsets.

- Accurate characterization of fracture fill, alteration styles, and joint condition/expression.

- Geomechanical core sampling for rock strength testing.

- Ability to validate dip angle of low confidence or partial sinusoids using a goniometer.

As core orienting technology continues to advance, methods are continuously developed and improved to provide cheap and reliable discontinuity orientation data. The appropriate application of core orienting techniques under different engineering circumstances can be challenging as scope of work, budget limitations, time constraints, logistics, ground conditions and expected outcomes must all be considered and different methods are more suitable under varying conditions. Optical and acoustic borehole imaging are best applied to more extensive drilling programs on a restricted or scrutinized budget as $\mathrm{OBI}$ and $\mathrm{ABI}$ are overall less expensive relative to other core orienting methods simply because it requires less man hours. As data turn-around time is generally slower, it may be more prudent to orient high-priority drill holes (i.e. acquiring rock fabric orientation data for kinematic analyses of a residual-state failure) with a faster method. Conversely, $\mathrm{OBI}$ and $\mathrm{ABI}$ are more suitable to acquiring data in heavily fractured or broken rock as they do not rely on the ability to confidently piece core together to collect accurate discontinuity orientations.

\section{CONCLUSIONS}

The findings in the paper were used to promote the companies of the orientation methods and help the user determine which method would be advantageous in different mining scenarios. It was not intended to promote one specific product, but to show how each method has its benefits and limitations. Errors and uncertainties introduced by personnel that may result in low-quality image logs or unreliable discontinuity orientation data include:

- Inexperienced or untrained survey operator (OBI/ABI only).

- Improper and/or infrequent maintenance of survey probes (OBI/ABI only).

- Improper data processing and optimization.

- Logging by inexperienced or poorly trained personnel that lack knowledge of the local geology and ground conditions.

- Inconsistent means of data collection by the core logger such as orientation of undesired structures. For example, measurable open joints are the primary structures of interest for slope stability analyses. Orientation of healed fractures and/or veins may result in inaccurate characterizations of the site's dominant rock fabric orientations.

- Careless handling of core from drill rod to sleeve.

- Inaccurate transfer of orientation from core (OBI/ABI exclusive).

This paper was constructed to help engineers, drillers and geologists better understand rock core orientation methods and how to determine which method is most appropriate for varying mining or civil engineering scenarios. The four methods discussed in this paper have all shown great potential towards obtaining true rock fabric orientations and have assisted in countless engineering projects to identify unstable conditions.

\section{REFERENCES}

[1] 2iC Australia Pty. (2006). Ezy-MarkTM Core Oreintation Grading Process. 2iC Australia Pty., Western Australia.

[2] Call, R. D., Savely, J. P., and Nicholas, D. E. (1976) Estimation of Joint Set Characteristics from Surface Mapping Data," Proc. 17th U.S. Symp. on Rock Mechanics, Snowbird, Utah, August 25-27, p. 2B2-1 - 2B2-9, also published by AIME, New York, Monograph \#1 on Rock Mechanics Applications in Mining, p. 66-73.

[3] Call, R.D. (1980) Clay Imprint Core Orientor Manual. Call and Nicholas, Inc, Tucson, AZ USA Revised 2008.

[4] Call, R.D., Savely J.P., Pakalins R. (1982) A simple core orientation technique. In C.O. Brawner (ed.), Proceeding of the Third International Conference on Stability in Surface Mining. Vancouver, Society of Mining Engineers of AIME, New York. pp. 465-481.

[5] Cylwik, S., Ryan, T., and Cicchini, P. (2011) Error Quantification in Oriented-Core Data and its Influence on Rock Slope Design. Slope Stability 2011: International Symposium on Rock Slope Stability in Open Pit Mining and Civil Engineering, Vancouver, Canada

[6] Gaillot, P., Brewer, T., Pezard, P. and En-Chao Yeh (2007). Borehole Imaging Tools - Principles and Applications. Deep Earth Sampling and Monitoring. V.1:p. 14 
[7] Reflex Instruments (2013). ACT I \& II TM Core Oreintation Process. Minerals Division of Imdex Limited. Perth, West Australia.

[8] Zajac, B. and Stock, J. (2000). Using Borehole Breakouts to Constrain the Complete Stress Tensor: Results from the Sijan Deep Drilling Project and Offshore Santa Maria Basin, California: Journal of Geophysical Research: Solid Earth. v. 105(B9): p. 21847-21849. 